Earth Interactions - Volume 13 (2009) - Paper No. 2 • Page 1

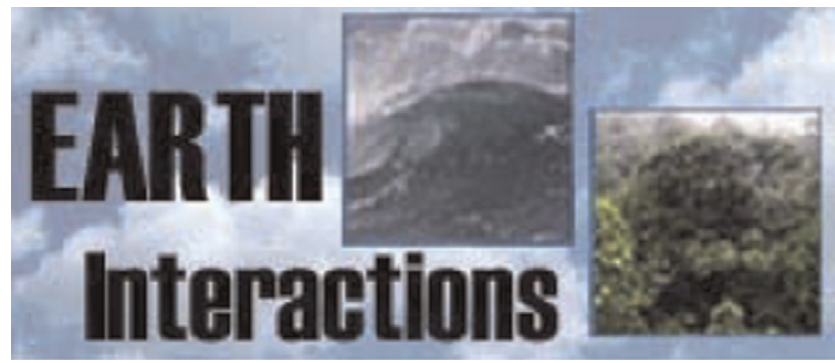

Copyright (c) 2008, Paper 13-002; 60291 words, 12 Figures, 0 Animations, 1 Tables. http://EarthInteractions.org

\title{
Energy Balance Partitioning and Net Radiation Controls on Soil Moisture- Precipitation Feedbacks
}

\author{
Aubrey R. Jones and Nathaniel A. Brunsell* \\ Department of Geography, University of Kansas, Lawrence, Kansas
}

Received 19 May 2008; accepted 14 January 2009

\begin{abstract}
A series of model runs using the University of Oklahoma's Advanced Regional Prediction System (ARPS) were conducted to investigate the relative impacts of energy balance partitioning and net radiation on soil moisture-precipitation feedbacks in the U.S. central plains and to examine how the dominant physical processes are affected by changes in mean soil moisture and spatial resolution. Soil temperature and Bowen ratio are influenced nonlinearly by soil moisture, and by varying the mean soil moisture in the model it was possible to examine the relationship between soil moisture and the scaling characteristics of these fields using the statistical moments. Information theory metrics were used to provide an indication of the uncertainty associated with varying model resolutions. It was determined that energy balance partitioning plays a dominant role in the occurrence of soil moisture-precipitation feedback, while net radiation was not impacted by mean soil moisture. A strong relationship was seen between soil moisture and the scaling properties of Bowen ratio, while soil moisture did not appear to influence the scaling characteristics of soil temperature. Spatial resolution had a large effect on the representation of boundary layer turbulence, with coarser resolutions unable to capture turbulent motions, which are necessary for convective processes. The ability of the model to capture boundary layer turbulence will alter the dynamics of soil moisture-precipitation feedback as the horizontal transport of moisture by turbulent motions will affect the spatial and temporal scales over which feed-
\end{abstract}

* Corresponding author address: N. A. Brunsell, Department of Geography, University of Kansas, 1475 Jayhawk Blvd., Lindley Hall 417, Lawrence, KS 66045-7613.

E-mail address: brunsell@ku.edu

DOI: $10.1175 / 2009 E I 270.1$ 
Earth Interactions - Volume 13 (2009) - Paper No. 2 • Page 2

back occurs. Higher-resolution runs are generally associated with a higher information content. This may provide a methodology for monitoring landatmosphere feedbacks via remotely sensed soil moisture and vegetation fields through statistical knowledge of the dependency of the resulting precipitation signal on soil moisture and vegetation fields at the resolution they were observed.

KEYWORDS: Soil moisture; Precipitation; Feedbacks

\section{Introduction}

Land-atmosphere interactions play an important role in determining regional weather and climate. Although this idea has been widely accepted, an understanding of the physical processes and the scales over which these interactions occur remains somewhat limited. Improving the current understanding of these relationships has important implications for increasing predictability of local weather and climate. According to Barros and Hwu (Barros and Hwu 2002), the basis of studies on land-atmosphere interactions is the idea that moisture and energy gradients across a landscape are associated with regional weather patterns over a wide range of spatial and temporal scales. Although soil moisture and vegetation impact the atmosphere through feedbacks with the land surface, the dominant processes driving these feedbacks have not been precisely determined and some disagreement still exists on what the primary mechanisms are.

Previous research has shown evidence for the existence of a soil moistureprecipitation feedback (Eltahir 1998; Findell and Eltahir 1997; Pal and Eltahir 2001), which can be either positive or negative (Brunsell 2006). A positive feedback would be characterized by an increase in precipitation resulting from high soil moisture or a continued suppression of precipitation resulting from anomalously dry soils. In the case of a negative feedback, increased precipitation would be associated with dry soils, while moist soils would act to suppress precipitation. In other words, a positive feedback acts to reinforce the initial change in the system while a negative feedback causes the system to diverge from the initial change.

By performing data analysis on observations of rainfall, temperature, and wetbulb temperature from the Amazon Region Micrometeorological Experiment, Pal and Eltahir (Pal and Eltahir 1996) found that both the frequency and magnitude of localized convective storms increased with the surface wet-bulb temperature. As the amount of moisture in the soil increases, the wet-bulb depression decreases. Lower lifting condensation level (LCL) heights should correspond to smallermagnitude wet-bulb depressions, which, according to Eltahir (Eltahir 1998), should enhance the likelihood for triggering moist convection and the occurrence of rainfall if all other factors remain the same.

Pal and Eltahir (Pal and Eltahir 2001) found evidence for the existence of a positive soil moisture-precipitation feedback in the U.S. Midwest. They showed that anomalously high soil moisture leads to an increase in the flux of high moist static energy air into the boundary layer from the surface through an increase in net surface radiation. An increase in the concentration of moist static energy occurs through a reduction in the height of the boundary layer, which occurs as a result of the anomalously moist soil. They attributed the increase in the frequency and magnitude of convective rainfall events to the increase in the amount of moist static energy per unit mass of air in the boundary layer. 
Earth Interactions • Volume 13 (2009) • Paper No. 2 • Page 3

Dong et al. (Dong et al. 2007) found a strong positive correlation between soil moisture and precipitation over grasslands at interannual time scales using the Global Soil Moisture Data Bank, which provides observed plant available soil moisture data for the top $1 \mathrm{~m}$ of soil. Although this may provide evidence for the existence of a feedback, it is important to note that while correlations imply a relationship they cannot be used to infer causality. Dong et al. (Dong et al. 2007) also suggest that the relationship between soil moisture and precipitation is a function of the geographic location. Differences in the relationship are attributed to varying atmospheric conditions, which are dependent on regional climate.

Although all of the previously mentioned studies involve positive feedbacks, evidence also supports the existence of negative soil moisture-precipitation feedbacks. Negative feedbacks are associated with an increase in sensible heat flux over dry soils, which can lead to an increase in turbulent mixing, boundary layer height, and convection (Findell and Eltahir 2003a). Findell and Eltahir (Findell and Eltahir 2003b), using a one-dimensional boundary layer model, found evidence for the existence of a negative soil moisture-precipitation feedback in the southwestern United States where the climate is dominated by a monsoon regime.

In another study, using data collected at the Blackwood Division of the Duke Forest near Durham, North Carolina, and a simple slab model, Juang et al. (Juang et al. 2007) found that conditions characterized by dry soil moisture and a dry atmosphere can induce convective precipitation. They suggested that a negative feedback may exist in the southeast region of the United States.

Cook et al. (Cook et al. 2006), using the Community Climate System Model, version 3 (CCSM3), found evidence for a negative feedback in southern Africa. Two simulations were run: a control case where soil moisture was allowed to interact dynamically with the atmosphere and a second case where soil moisture was defined such that evapotranspiration (ET) would not be water limited. A decrease in precipitation was associated with the moist case when compared to the control case.

A study involving 12 atmospheric general circulation model (AGCM) groups was coordinated by the Global Land-Atmosphere Coupling Experiment (GLACE) to detect regions of strong coupling between soil moisture and precipitation (Koster et al. 2004). The strongest coupling occurred in transition zones between wet and dry climates. This was attributed to the ability of boundary layer moisture to trigger convection in these areas and the fact that evaporation is substantial enough yet still sensitive to the soil moisture state.

Knowing which physical processes are involved and identifying key features responsible for soil moisture-precipitation feedback is crucial for improving predictability of precipitation and other related variables and events. Pal and Eltahir (Pal and Eltahir 2001) emphasized the importance of the impacts of soil moisture on the energy and water budgets in determining the strength of soil moistureprecipitation feedback. Eltahir (Eltahir 1998) hypothesized the change in albedo and Bowen ratio (the ratio of sensible heat to latent heat) as being the fundamental basis of the feedback. The foundation of this argument is that, as soil moisture increases, the albedo decreases because of a darkening of the soil, which leads to an increase in net solar radiation. The Bowen ratio decreases as latent heat becomes larger than sensible, resulting in a decrease in surface temperature and an increase 
in the water vapor content of the boundary layer. Therefore, when soil moisture is high, the decrease in albedo and Bowen ratio results in an increase in the net radiation at the surface (Eltahir 1998).

Teuling and Seneviratne (Teuling and Seneviratne 2008), using albedo estimates from the Moderate Resolution Imaging Spectroradiometer (MODIS) for the 2003 heat wave and drought over Europe, found that albedo responded oppositely to soil moisture anomalies in the visible and near-infrared portions of the spectrum. Teuling and Seneviratne (Teuling and Seneviratne 2008) determined that the impacts of dry soil alone would lead to higher albedos; however, the response of vegetation to water stress resulted in a lower albedo. In this case, the results did not support the existence of an albedo feedback induced by drought. This agrees with the findings of Brunsell (Brunsell 2006) which, based on 8 years of Advanced Very High Resolution Radiometer (AVHRR) data, suggest that vegetation plays a dominant role in determining local feedbacks.

Obtaining data at the appropriate resolution for the study of land-atmosphere interactions can pose a significant challenge. There are some ways to potentially overcome this issue, including the use of scaling coefficients calculated from spatial fields that exhibit statistical self-similarity. The idea of statistical selfsimilarity has been studied across a wide range of fields, including physics, ecology, hydrology, and atmospheric science. It has gained additional attention with the extensive use of remotely sensed data because of the potential for widespread application. By performing a scaling analysis it may be possible to infer variability at any other resolution if the field exhibits self-similarity, that is, scale invariance. A process is said to be scaling, or self-similar, if the process behaves similarly at both small and large scales, that is, the statistical properties of the field do not vary as a function of scale (Bloschl 2001).

The idea of spatial scaling is certainly not new and much work has already been done, specifically on soil moisture and precipitation (Deidda 1999; RodriguezIturbe et al. 1995; Waymire 1985; Western and Bloschl 1999). Remotely sensed fields are commonly used because of the availability of data where surface measurements either do not exist or are unavailable at consistent spatial and temporal scales. Field measurements of surface soil moisture, for example, cannot be taken over large areas or with the temporal frequency required for many studies. Although remote sensing has improved the spatial and temporal resolution of data for variables such as soil moisture, complications still arise as a result of resolution. Differences in resolution make it difficult to validate remotely sensed data with surface measurements or larger-scale models (Brunsell and Gillies 2003b).

Statistical self-similarity can potentially be used to circumvent resolution issues associated with remotely sensed data. A process is defined as self-similar if

$$
\varphi(x)=\lambda^{-\beta}[\varphi(\lambda x)]
$$

where $\phi$ represents the field, $x$ is the spatial scale, $\lambda$ is the ratio of the large-scale $\lambda x$ to the small-scale $x$, and $\beta$ is the scaling exponent (slope) (Bloschl 1996). If a field exhibits statistical self-similarity, it can be used to infer model variability at any other resolution (Halley et al. 2004). 
Earth Interactions • Volume 13 (2009) • Paper No. 2 • Page 5

In determining the scaling properties of a field, some studies have focused on the variance (Baldocchi et al. 2005) and others on high-order statistical moments (Brunsell and Gillies 2003a; Dubayah et al. 1997). Using high-order moments provides more information on the statistical properties and structure of the field as opposed to the variance. For a process or field to exhibit simple scaling, a plot of $\beta$ versus order of moment must be linear (Gupta and Waymire 1990). If the process is truly scale invariant, then the amount of variability in the field does not change as a function of scale. For a multiscaling process the amount of variability changes as a function of scale, which is seen as a nonlinear change in $\beta$ with order of moment. A field or process may exhibit either scaling or multiscaling characteristics, or it may be scale dependent, meaning that knowledge at one scale cannot be used to predict statistical properties at other scales.

An investigation of the scaling properties of soil moisture performed by Jones and Brunsell (Jones and Brunsell 2008, manuscript submitted to Theor. Appl. Climatol., hereafter $\mathrm{JoBr}$ ) found high temporal variability of scaling coefficients. It is well known that soil moisture strongly influences other surface variables, including soil temperature and Bowen ratio, in a nonlinear way. Here the influence of varying mean soil moisture on the scaling characteristics of 1000 to 1400 LT temporally averaged soil temperature and Bowen ratio is examined. Emphasis is placed specifically on how these scaling relationships vary temporally, as this has important implications for the use of remotely sensed fields in future research. If the scaling relationships remain relatively constant through time, generalizations can be made and applied to remotely sensed fields to provide either input to numerical models or fields that can be readily compared with model output for validation purposes.

The primary goals of this paper are to investigate the relative importance of energy balance partitioning and net radiation in soil moisture-precipitation feedbacks, to examine how the dominant physical processes are impacted by changes in mean soil moisture and spatial resolution, and to investigate the scaling characteristics of Bowen ratio and soil temperature and determine how they are influenced as a function of soil moisture.

\section{Model description}

To examine the physical processes involved in soil moisture-precipitation interactions and to investigate the impacts of mean soil moisture on the scaling properties of soil temperature and Bowen ratio, a series of model runs were conducted using the University of Oklahoma's Advanced Regional Prediction System (ARPS). ARPS is a three-dimensional, nonhydrostatic, compressible model that was developed at the Center for Analysis and Prediction of Storms (CAPS) to be used for real-time forecasting and to serve as a tool for research (Xue et al. 2000; Xue et al. 2001).

To examine the impacts of mean soil moisture and model resolution on soil moisture-precipitation interactions, a suite of 15 model runs was conducted (Table 1). The horizontal resolutions (i.e., model grid cell size) used in this study include 1, 2, 4,8 , and $16 \mathrm{~km}$. At each of these resolutions initial soil moisture was varied from field capacity (FC) to wilting point (WP), with one intermediate value (50FC). At FC, by definition only $39.3 \%$ of the soil is occupied by water, while only $15.4 \%$ of 
Earth Interactions • Volume 13 (2009) • Paper No. 2 • Page 6

Table 1. Suite of 15 model runs conducted with varying resolutions $(R)$ and initial soil moisture values using the ARPS.

\begin{tabular}{cccc}
\hline$R$ & FC & $50 \%$ of FC $(50 \mathrm{FC})$ & WP \\
\hline $1 \mathrm{~km}$ & FC, $1 \mathrm{~km}$ & $50 \mathrm{FC}, 1 \mathrm{~km}$ & WP, $1 \mathrm{~km}$ \\
$2 \mathrm{~km}$ & FC, $2 \mathrm{~km}$ & $50 \mathrm{FC}, 2 \mathrm{~km}$ & WP, $3 \mathrm{~km}$ \\
$4 \mathrm{~km}$ & FC, $4 \mathrm{~km}$ & $50 \mathrm{FC}, 4 \mathrm{~km}$ & WP, $4 \mathrm{~km}$ \\
$8 \mathrm{~km}$ & FC, $8 \mathrm{~km}$ & $50 \mathrm{FC}, 8 \mathrm{~km}$ & WP, $8 \mathrm{~km}$ \\
$16 \mathrm{~km}$ & FC, $16 \mathrm{~km}$ & $50 \mathrm{FC}, 16 \mathrm{~km}$ & WP, $16 \mathrm{~km}$ \\
\hline
\end{tabular}

the soil is occupied by water at WP. The specific values used include 0.35 for FC, 0.13 for $50 \mathrm{FC}$, and 0.09 for WP.

A standard midlatitude summer sounding, modified to ensure westerly winds at all levels, was used to initialize all runs. Soil and vegetation properties are homogeneous across the domain, with a soil type of sandy loam and the vegetation being grassland. A leaf area index (LAI) of 0.31 was used, based on measured values obtained at the Ameriflux site located on the Konza Prairie (J. M. Ham 2008, personal communication).

ARPS includes a two-layer diffusive soil-vegetation model with coupled surface energy budget equations. The time rate of change in volumetric soil moisture near the soil surface is a function of the precipitation and evaporation rates at the ground and the transfer of surface soil moisture with moisture from the deep soil layer. For further description of the land surface scheme used in ARPS, please see Xue et al. (Xue et al. 2000; Xue et al. 2001).

Convective processes cannot be explicitly resolved at resolutions much coarser than $1 \mathrm{~km}$ (Chen and Avissar 1994). As a result, the Kain-Fritch Weather Research and Forecasting (WRF) parameterization scheme was used in the 4-, 8-, and 16-km runs. This scheme was chosen because it is more suitable for higher-resolution grids and has the ability to generate sources of rainwater and snow, which are fed back to grid-scale variables (Xue et al. 2001).

As precipitation resulting from soil moisture feedbacks is convective in nature and synoptic impacts are not of interest in this particular study, one-way interactive grid nesting was chosen. Two-way nesting would be necessary to capture mesoscale impacts on the synoptic environment, which would then feedback to modify the mesoscale environment. For the purposes of this study these mesoscale interactions are unnecessary because we are attempting to ascertain physical processes associated with soil moisture-precipitation feedbacks and not the accurate simulation of a particular synoptic case study.

Coarse runs for the one-way nesting were conducted over the outer domain (Figure 1), which covers an area of $4194304 \mathrm{~km}^{2}$, using a horizontal resolution of $16 \mathrm{~km}$ over a period of 20 days beginning with 18 August. These runs were initialized using the same characteristics as the inner grid, which covers an area of $16384 \mathrm{~km}^{2}$, to maintain comparability between all runs. The first four days of each coarse-resolution run were regarded as spinup and discarded, leaving 16 days to force the inner grid at the 1-, 2-, 4-, 8-, and 16-km resolutions. The vertical grid was composed of 83 layers, with higher resolution at the surface (approximately $100 \mathrm{~m}$ ), decreasing exponentially with distance from the surface, with a resolution of approximately $500 \mathrm{~m}$ at the top of the model domain. 


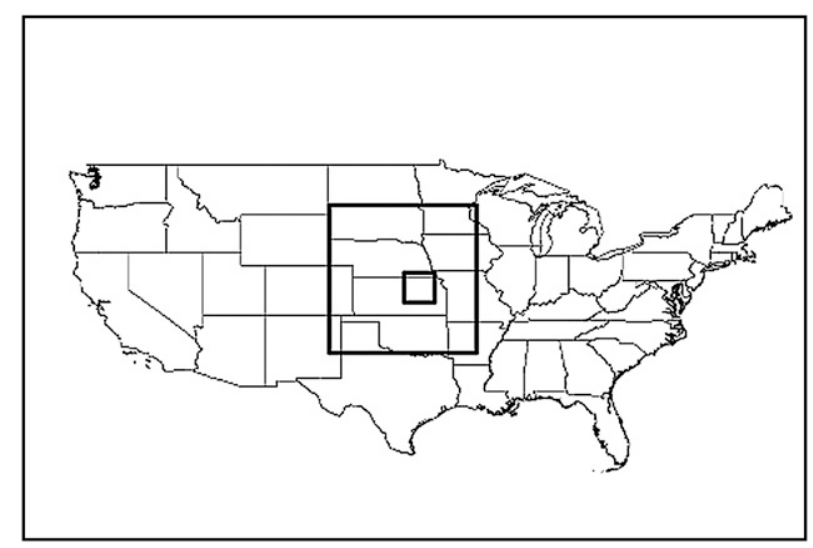

Figure 1. Model domain centered on the Konza Prairie in northeastern Kansas.

\section{Site description}

The model domain focuses on the U.S. central plains, which was selected because of its importance as an agricultural region. Altering precipitation regimes will impact soil moisture variability, which may then alter precipitation patterns through land-atmosphere feedbacks. This has potential ramifications for agricultural production in the central plains, where irrigation practices alter soil moisture patterns. Studies such as this may provide insight into the potential impacts of irrigation on region climate. Understanding the physical processes that drive soil moisture-precipitation feedbacks has important implications for improved forecasting of crop yields and water availability for both agricultural and urban uses.

The center of the domain was specifically placed on the Konza Prairie, which covers an area of approximately $34.87 \mathrm{~km}^{2}$ (Lett and Knapp 2005) in the Flint Hills of northeastern Kansas near Manhattan, Kansas $\left(39^{\circ} 05^{\prime} \mathrm{N}, 96^{\circ} 35^{\prime} \mathrm{W}\right)$. The land is owned by the Nature Conservancy and managed by Kansas State University as a National Science Foundation (NSF) Long-Term Ecological Research Station (LTER). Much of the research conducted at Konza focuses on climate and the current management program includes periodic burning and the reintroduction of native grazers (i.e., buffalo) (Kaste et al. 2006).

The climate can be characterized as temperate midcontinental, with cold, dry winters and warm, wet summers (Nippert et al. 2006) and with annual temperatures ranging from a low of $-2.7^{\circ} \mathrm{C}$ in January to a high of $26.6^{\circ} \mathrm{C}$ in July (Fay et al. 2003). Approximately $75 \%$ of the mean annual precipitation $(835 \mathrm{~mm})$ falls during the growing season between April and September (Lett and Knapp 2005).

Being located within the Flint Hills region, the soils are rich and thin, overlaid on alternating layers of limestone and shale. The soil types vary in the area from Ustolls to Udolls including deep silt loam and silty clay loams soils. Steep-sided lowlands and flat upland ridges characterize the terrain at Konza (Lett and Knapp 2005). Native tallgrass prairie comprises the majority of the vegetation; with perennial warm season grasses such as little bluestem (Schizachyrium scoparium Michx), big bluestem (Andropogon gerardii Vitman), Indian grass (Sorghastrum nutans (L.) Nash), and switchgrass (Panicum virgatum L.) dominating (Kaste et al. 2006). 
Earth Interactions - Volume 13 (2009) - Paper No. 2 • Page 8

\section{Methodology}

\subsection{Net radiation versus energy balance partitioning}

To evaluate how net radiation $\left(R_{n}\right)$ and energy balance partitioning change as a function of model resolution and mean soil moisture, the root-mean-square error (RMSE) was calculated between the 1-km runs and every other resolution:

$$
\operatorname{RMSE}=\sqrt{\frac{\sum_{i=1}^{n}\left(x_{1, i}-x_{2, i}\right)^{2}}{n}}
$$

where $n$ is the number of points and $x_{1}$ and $x_{2}$ are the variables between which the error is calculated. The 1-km runs were used as "truth," as they are able to resolve more of the small-scale physical processes and capture more of the variability in surface properties, which can potentially impact net radiation and partitioning into sensible and latent heat fluxes. Although the RMSE is typically used as an error estimate, here it will be used as a metric to evaluate differences as a function of model resolution.

Previous studies have argued that soil moisture-precipitation feedbacks are driven by an increase in net radiation associated with a lowering of the albedo over moist soils (Eltahir 1998). To investigate the validity of this argument, scatterplots of soil moisture versus net radiation were constructed. Additionally, scatterplots of soil moisture versus Bowen ratio were constructed to look for soil moisture impacts on surface energy balance partitioning, which we hypothesize to be the dominant process impacting the feedback mechanism (Brunsell 2006).

\subsection{Lagged correlations}

We hypothesize that changes in energy balance partitioning will impact precipitation more prominently than variation in net radiation through a soil moisture feedback. JoBr, using a mesoscale model with varying resolutions and initial mean soil moisture values, found evidence for a positive soil moisture feedback in the central Great Plains. Runs initialized at field capacity consistently exhibited higher total precipitation amounts and had a higher frequency of events. Lagged correlations were used to show the temporal scales over which the feedback mechanism occurs.

Here lagged correlations will be used to examine the temporal scales over which latent and sensible heat fluxes, Bowen ratio, and net radiation impact precipitation. Temporally lagged correlations are given by

$$
\begin{gathered}
\hat{R}_{x y}(m)=\sum_{n=0}^{N-m-1} x_{n+m} y_{n}, \quad m \geq 1, \\
\hat{R}_{x y}(m)=\hat{R}_{y x}(-m), \quad m<0,
\end{gathered}
$$


Earth Interactions - Volume 13 (2009) - Paper No. 2 • Page 9

where $\hat{R}_{x y}$ is the correlation, $x$ and $y$ are stationary random variables, $N$ is the number of points, and $m$ is the lag. Positive lags indicate that precipitation is leading the other variable, while negative lags indicate that precipitation is being led by the other variable.

The day at which the maximum lag correlation occurs is examined as a function of model resolution and mean soil moisture to determine the time scale associated with land-atmosphere feedbacks. Feedbacks involving dry versus wet soil may occur on different temporal scales. This is highly likely as the physical processes involved in the feedback differ as a function of soil moisture level as discussed in section 1. To determine whether there are consistent trends as a function of model resolution and mean soil moisture, the day of maximum lagged correlation was found for each pixel, neglecting the zero lag, and then spatially averaged for each model run.

\subsection{Information content}

As another method for assessing variability between individual model runs, entropy is calculated:

$$
H(x)=\frac{-\sum_{i=1}^{n} p_{i}(x) \log _{2} p_{i}(x)}{\log _{2}(n)},
$$

where $H$ is the entropy, $x$ is the variable of interest, and $p_{i}(x)$ is the probability mass function or the probability that $x$ is exactly equal to some value (Shannon 1948). An information metric $H$ [i.e., a measure of the average information content (in bytes)] provides an indication of how much uncertainty is associated with a random variable (Brunsell and Young 2008; Brunsell et al. 2008). A higher $H$ corresponds to less useable information. This presumably will vary as a function of model resolution and also may vary as a function of initial soil moisture. Higher resolutions are expected to correspond with lower values of $H$ as they are able to capture more heterogeneity in surface characteristics and are better able to resolve smaller-scale physical processes than coarser resolutions, resulting in a higher information content.

It is also possible to compute the amount of entropy contained within a system of two independent variables. The joint entropy of two variables is given by

$$
\mathrm{JE}(x, y)=-\sum_{i, j} p(i, j) \log _{2} p(i, j)
$$

where JE is the joint entropy and $p(i, j)$ is the joint probability of $i$ for the first variable and $j$ for the second. The joint entropy must always be greater than or equal to the amount of entropy associated with the individual variables, as adding another variable cannot decrease the amount of information within the system. We

calculate the joint entropy as an intermediate step to obtaining the mutual information content of the two variables. 
Earth Interactions • Volume 13 (2009) • Paper No. 2 • Page 10

The entropy and joint entropy can be used to calculate the mutual information content, or mutual dependence, of two variables:

$$
I(x, y)=H(x)+H(y)-\mathrm{JE}(x, y),
$$

where $I$ is the mutual information content, $H(x)$ is the entropy of $x, H(y)$ is the entropy of $y$, and $\operatorname{JE}(x, y)$ is the joint entropy of $x$ and $y$. This provides a measure of the amount of information known about one variable given the other (i.e., redundancy), or the decrease in uncertainty in one variable given the other.

The spatial entropy was calculated at an hourly time scale for soil moisture, precipitation, Bowen ratio, net radiation, and sensible and latent heat flux and then averaged to the daily time scale. The mutual information content was then calculated hourly and averaged to daily values for soil moisture and precipitation, soil moisture and Bowen ratio, and soil moisture and net radiation. This analysis will provide an indication as to the strength of the relationship between these variables and how it varies temporally as a function of mean soil moisture and spatial resolution.

\subsection{Turbulent mixing and boundary layer height}

At coarser resolutions the model may be unable to capture mesoscale circulations resulting from heterogeneity in surface characteristics, which may play an important role in the dynamics of soil moisture-precipitation feedback mechanisms. As the main objective of this study was to examine the physical processes involved in the feedback and determine which have a dominant role, an investigation of the relative impact of horizontal versus vertical motions is performed. This presumably will vary as a function of model resolution, as mentioned above, but also as a function of mean soil moisture. Because of lower sensible heat fluxes, FC runs are expected to have less turbulent mixing and as a result a lower boundary layer height. To verify this hypothesis, the spatially averaged vertical profile of the ratio of 1000 to 1400 LT temporally averaged vertical to horizontal turbulent mixing coefficients for momentum $\left(\mathrm{km}_{v} / \mathrm{km}_{h}\right)$ was calculated, and then the profiles for each of the 12 days were temporally averaged for each model run.

\subsection{Spatial scaling}

To determine the variation in spatial scaling as a function of mean soil moisture and resolution, a scaling analysis is performed on model-generated fields of 1000 to 1400 LT temporally averaged soil temperature and Bowen ratio. Although there are different methodologies for determining the scaling properties, the statistical moments are calculated, as this method provides information on the spatial structure of the field. Other studies have chosen only to examine how the variance scales, but calculating the moments will allow us to more fully characterize the statistical scaling relationships. If a scaling relationship does exist, it can then be used to calculate any of the statistical moments at any other resolution. 
Earth Interactions - Volume 13 (2009) - Paper No. 2 • Page 11

We performed this analysis on 1000 to 1400 LT temporally averaged soil temperature and Bowen ratio by calculating the first six statistical moments. The first moment is given by Equation (8):

$$
\bar{x}=\frac{1}{N} \sum x_{i}
$$

the second moment by Equation (9):

$$
x^{2}=\frac{1}{N} \sum\left(x_{i}-\bar{x}\right)^{2}
$$

and Equation (10) is used to obtain the third through sixth moments:

$$
x^{n}=\frac{\frac{1}{N} \sum\left(x_{i}-\bar{x}\right)^{n}}{\sigma^{n}},
$$

where $n$ is the order of moment, $N$ is the number of points, $\bar{x}$ is the mean, and $\sigma$ is the standard deviation. The six moments are plotted versus resolution on a log-log scale:

$$
\log (\varphi)=\log (\alpha)+\beta \log (\lambda)
$$

where $\varphi$ is the variable of interest, $\lambda$ is the spatial resolution, $\beta$ is the scaling exponent (slope), and $\alpha$ is the intercept, determined by linear regression (Brunsell and Gillies 2003a). The $\beta$ values are then plotted versus order of moment on a log$\log$ scale.

To ascertain the model's ability to capture the dominant processes controlling soil moisture-precipitation feedbacks, soil temperature and Bowen ratio fields that have been obtained through individual model runs at varying resolutions are used, rather than beginning with one field and aggregating it to other resolutions. The majority of scaling analyses, regardless of the variable of interest, have been based on fields aggregated, or filtered, from an initial resolution. This will undoubtedly have a large impact on the scaling properties of the field.

In addition to quantifying the scaling coefficients at one point in time, temporal variability in the spatial scaling relationship is examined. We are interested in observing the scaling characteristics based on fields that are completely independent of one another and examining how these characteristics vary temporally. The ultimate goal is to determine whether there are scaling properties intrinsic to the field that will allow for the estimation of statistical properties at resolutions other than the modeled resolutions at different times. This has important implications for the use of remotely sensed data as input to numerical models and for the comparison of model output with remotely sensed fields. 

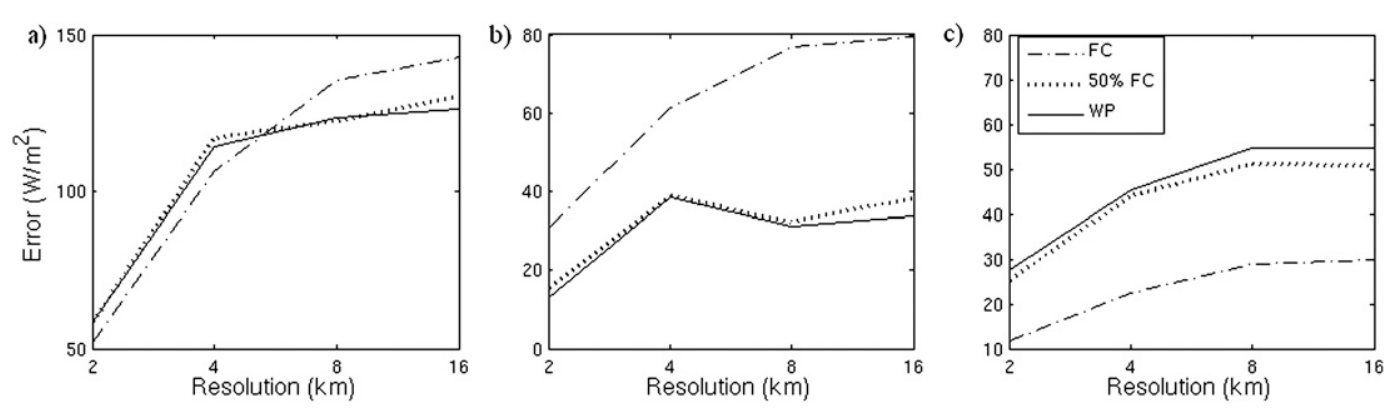

Figure 2. The RMSE was calculated between 1-km runs and every other resolution for (a) net radiation, (b) latent heat flux, and (c) sensible heat flux.

\section{Results}

\section{1. $\mathbf{R}_{\mathbf{N}}$ versus energy balance partitioning}

Plots of RMSE for net radiation, latent, and sensible heat flux are shown in Figure 2. For net radiation (Figure 2a) RMSE exhibits a positive trend as a function of resolution; however, mean soil moisture does not appear to have an impact on the RMSE. This does not hold for latent (Figure 2b) and sensible heat (Figure 2c), where clear trends are associated with mean soil moisture. FC runs have consistently higher RMSE values for latent heat and lower values for sensible heat. They also maintain an increasing trend with resolution. The 50FC and WP runs are distinctly different from FC runs but behave similarly to one another for net radiation, latent, and sensible heat. Both 50FC and WP are associated with an increasing trend for sensible heat, although there is a slight decrease between 2 and $4 \mathrm{~km}$ for latent heat flux.

Scatterplots of Bowen ratio versus soil moisture (Figures $3 \mathrm{a}-\mathrm{c}$ ) exhibit a strong relationship, with Bowen ratio values decreasing as soil moisture increases. This is expected, with higher latent heat fluxes associated with higher soil moisture levels. This demonstrates that soil moisture does have a significant effect on energy balance partitioning. However, scatterplots of net radiation versus soil moisture (Figures 3d-f) do not show a clear relationship. Here an increase in net radiation does not appear to be associated with higher soil moisture values, which would be expected from a lowering of the albedo over moist soils. This supports our hypothesis that energy balance partitioning plays a dominant role in land-atmosphere feedbacks.

\subsection{Information theory metrics}

Time series plots of entropy at each initial soil moisture value and spatial resolution are shown for latent heat and net radiation in Figure 4. For latent heat, entropy values for FC runs are clustered between 0.8 and 0.9 , while the 50FC and WP runs show a larger range of values and higher temporal variability. In the case of net radiation, 4-, 8-, and 16-km runs show similar changes in entropy values over time regardless of initial soil moisture. The $1-\mathrm{km}$ runs generally have the lowest values. 

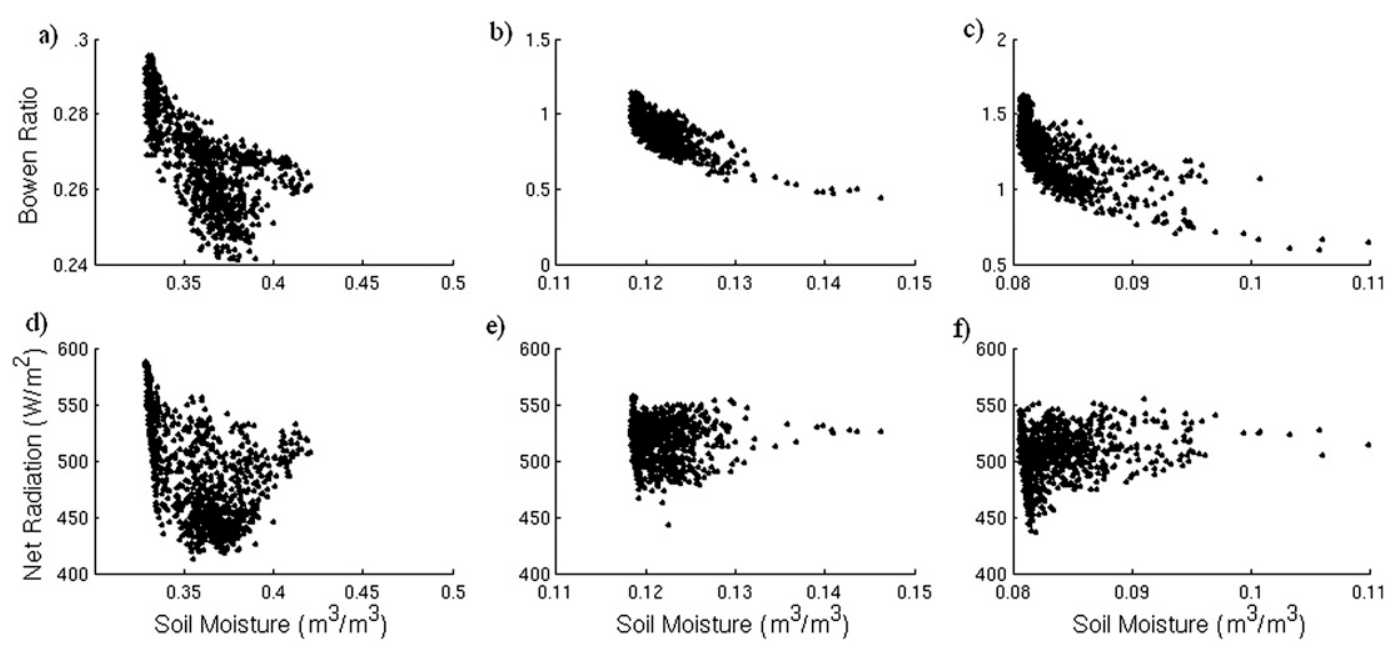

Figure 3. Scatterplots of soil moisture vs Bowen ratio (a) FC, (b) 50FC, and (c) WP and soil moisture vs net radiation (d) FC, (e) 50FC, and (f) WP for the 4-km runs.

Entropy plots for sensible heat and Bowen ratio (not shown) behaved similarly to those of LE. FC exhibits a clear increase in entropy values with resolutions. This trend generally holds for 50FC and WP. Values of $H$ are relatively similar for all resolutions at 50FC and WP, while FC runs show a greater range of values.

Joint entropy was then calculated between soil moisture and Bowen ratio and soil moisture and net radiation. This allowed for the examination of the mutual
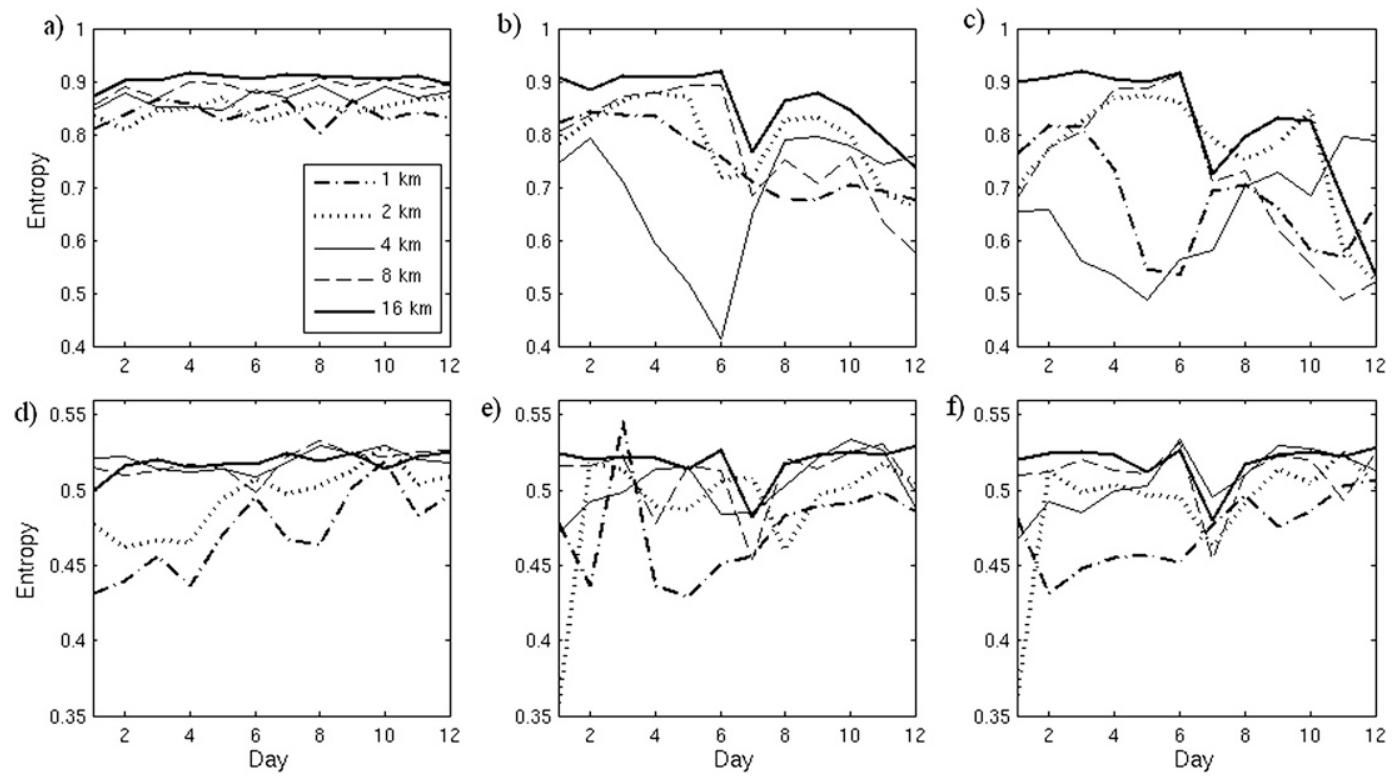

Figure 4. Time series of daily averaged entropy for latent heat flux (a) FC, (b) 50FC, and (c) WP and net radiation (d) FC, (e) 50FC, and (f) WP. 

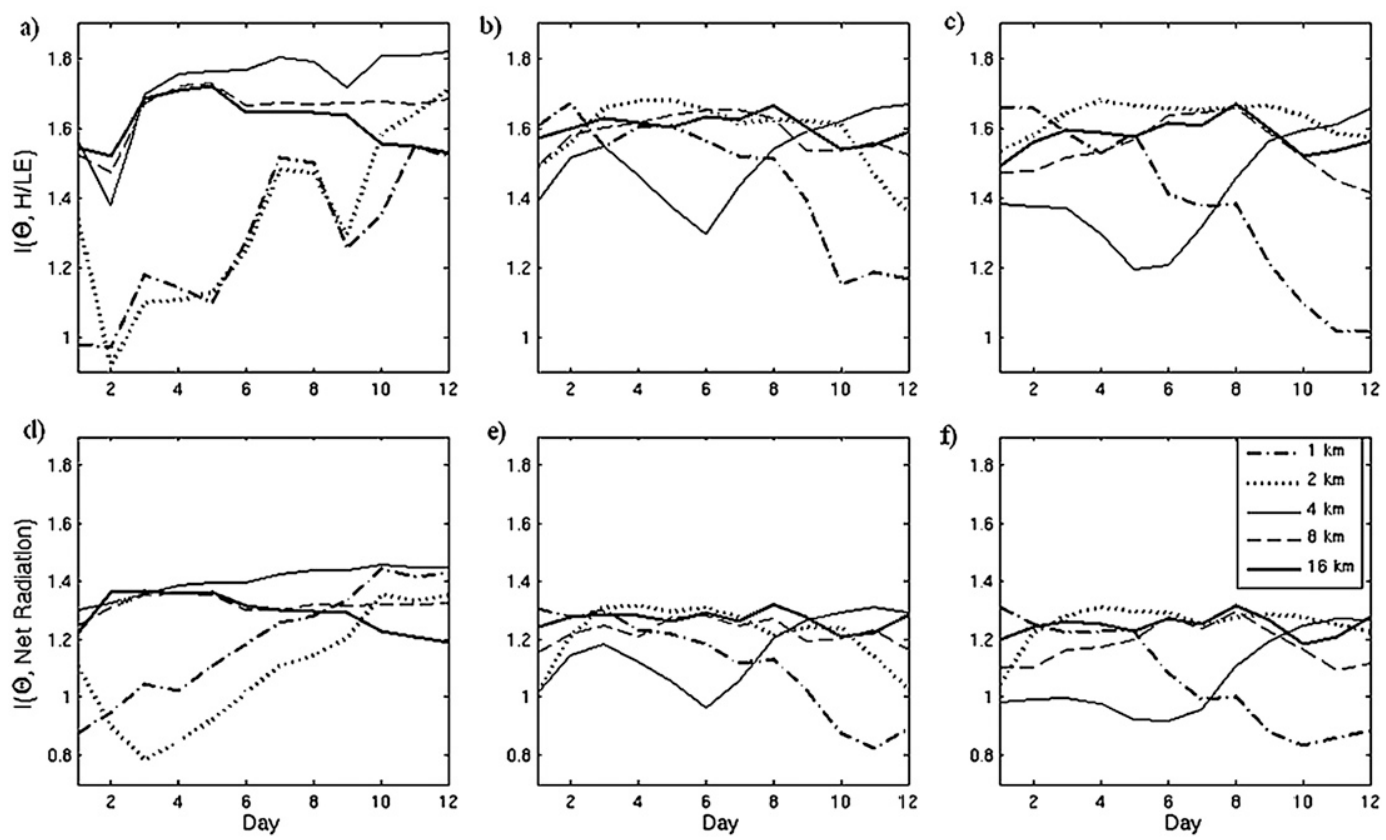

Figure 5. Time series plots of daily averaged mutual information content between soil moisture and Bowen ratio (a) FC, (b) 50FC, and (c) WP and between soil moisture and net radiation (d) FC, (e) 50FC, and (f) WP.

information content $(I)$. Figures $5 \mathrm{a}-\mathrm{c}$ show a time series of $I$ for soil moisture and Bowen ratio. For FC the 1- and 2-km runs exhibit the lowest values of $I$ with similar temporal trends. 50FC and WP plots look extremely similar, with no obvious trend as a function of resolution. The value of $I$ for $1-\mathrm{km} 50 \mathrm{FC}$ and WP runs generally decreases over time. Time series of $I$ for soil moisture and net radiation (Figures $5 \mathrm{~d}-\mathrm{f}$ ) closely resemble those for soil moisture and Bowen ratio, with the main difference being lower values of $I$ for all model runs.

\subsection{Lagged correlations}

Lagged correlations were calculated between precipitation and each of the following variables: Bowen ratio, latent heat flux, sensible heat flux, and net radiation. FC runs exhibit the highest correlations for all variables. Figure 6 shows the lagged correlation between Bowen ratio and precipitation for FC. Values either remain similar or decrease as soil moisture decreases. For the 1- and 2-km FC runs, correlation values oscillate but consistently remain between 0.3 and 0.5 to approximately -10 days. Correlation values for $4-\mathrm{km}$ FC are above 0.5 for the first couple positive lags and then remain at or above 0.4 out to approximately +5 days.

Plots are not shown for latent heat flux, sensible heat flux, or net radiation as they exhibit the same general characteristics as those of Bowen ratio. The highest correlation values are consistently associated with1-km FC runs, and correlation values for 50FC and WP runs are extremely similar to one another. 


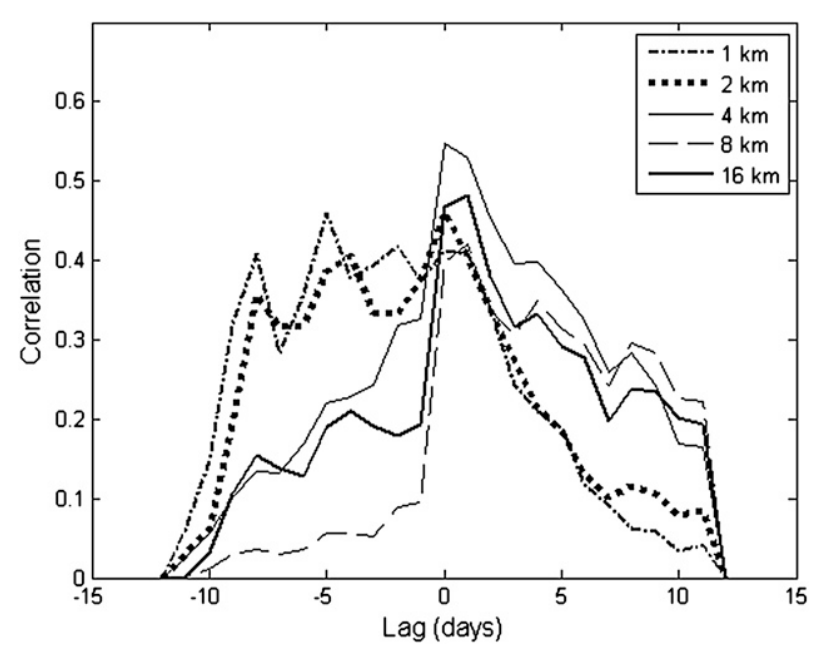

Figure 6. Temporally lagged correlation between daily total precipitation and 1000 to 1400 LT temporally averaged Bowen ratio for FC.

For the lagged correlations between latent heat and precipitation, the highest correlation values remain at or above 0.4 out to approximately -7 to -8 days. Correlation values for sensible heat flux are generally lower than those of latent heat flux. Plots of lagged correlation between net radiation and precipitation resemble those of latent heat flux with values between 0.4 and 0.5 for $1-\mathrm{km} \mathrm{FC}$ extending out to -5 lags. 50FC and WP runs are very similar, except for a peak in the correlation in the $1-\mathrm{km}$ WP run at around -6 or -7 lags.

As a way to asses the timing of the feedback, the day of maximum lagged correlation is examined. Figures $7 \mathrm{a}-\mathrm{c}$ show the spatial average of day of maximum lagged correlation for Bowen ratio and precipitation as a function of spatial resolution. The 50FC and WP plots exhibit a distinct trend, with the day of maximum lagged correlation shifting from negative values in the 1-km runs to increasingly positive values as resolution become coarser. The spatial standard deviation also generally decreases as a function of resolution. The lag for the 1-km FC run is larger than that of the 50FC and WP runs, and the decrease in standard deviation occurs much more rapidly with resolution, approaching zero.

The day of maximum lagged correlation between latent heat and precipitation (Figures 7d-f) changes sign for 50FC and WP runs as resolution increases, shifting from approximately -4 to +5 . Spatial standard deviations are once again smaller for $\mathrm{FC}$ runs, and there is also a shift in sign for day of maximum lagged correlation in FC runs. The trend is not as large or consistent as in 50FC and WP, with a positive trend from 1 to $8 \mathrm{~km}$, and then a slight decrease occurs at $16 \mathrm{~km}$. Day of maximum lagged correlation plots (Figures $7 \mathrm{~g}-\mathrm{i}$ ) are nearly identical to those of latent heat flux; however, the shift between the 1- and 2-km runs for 50FC and WP is more dramatic for sensible heat flux.

Plots of day of maximum lagged correlation between net radiation and precipitation (Figures $7 \mathrm{j}-1$ ) show a large change in day as a function of resolution, with the largest changes occurring in the 50FC and WP runs. The 1-km runs also show a 

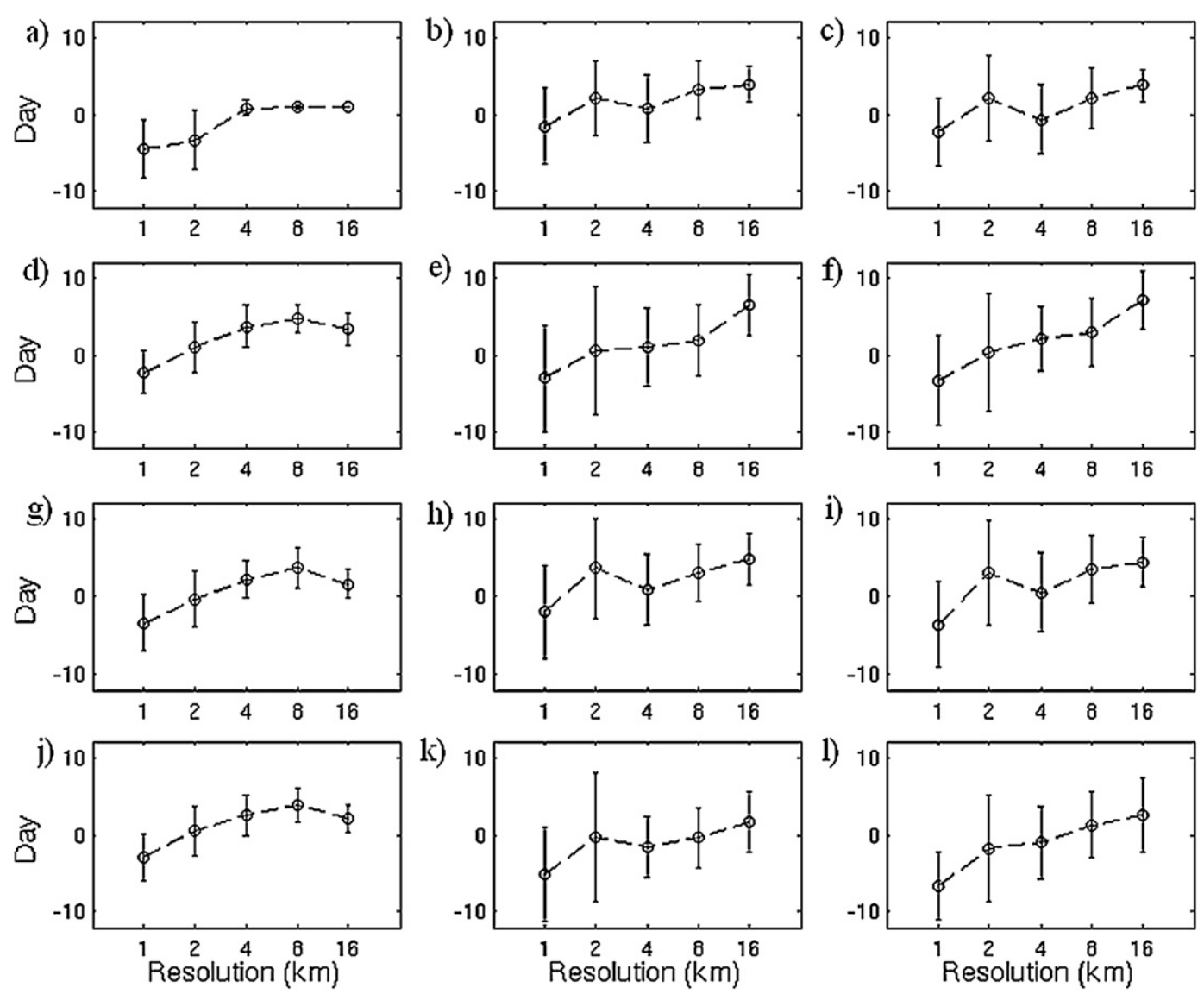

Figure 7. Spatially averaged day of maximum lagged correlation between daily total precipitation and 1000 to $1400 \mathrm{LT}$ temporally averaged Bowen ratio (a) FC, (b) 50FC, and (c) WP; latent heat flux (d) FC, (e) 50FC, and (f) WP; sensible heat flux (g) FC, (h) 50FC, and (i) WP; net radiation (j) FC, (k) 50FC, and (I) WP.

trend in day as a function of initial soil moisture. In looking only at the 1-km runs, there is a shift from around -3 to -5 days in the $\mathrm{FC}$ run to around -6 or -7 days in the WP runs.

\subsection{Turbulent mixing and boundary layer depth}

Figure 8a provides an example of the spatially and temporally averaged vertical profiles of $\mathrm{km}_{v} / \mathrm{km}_{h}$. FC profiles are consistently characterized by a smaller ratio, as was hypothesized. Higher sensible heat flux in 50FC and WP runs leads to increased turbulent mixing with larger vertical motions. These profiles indicate a much larger boundary layer depth associated with 50FC and WP runs.

Resolution also has a significant impact on the ratio of $\mathrm{km}_{v} / \mathrm{km}_{h}$. Figure $8 \mathrm{~b}$ shows vertical profiles for each spatial resolution at WP. The ratio consistently decreases as the spatial resolution becomes coarser, which presumably will have a 

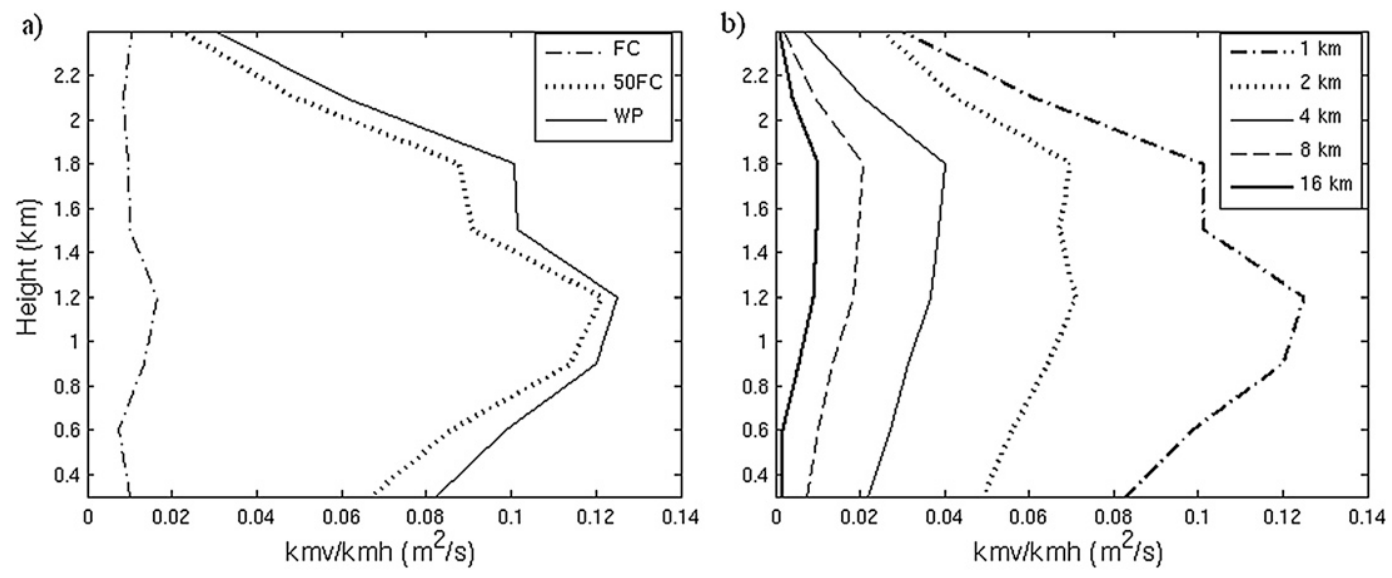

Figure 8. Spatially and temporally averaged vertical profiles of (a) $\mathrm{km}_{v} / \mathrm{km}_{h}$ for each mean soil moisture at 1-km spatial resolution and (b) WP $\mathrm{km}_{v} / \mathrm{km}_{h}$ at each spatial resolution.

large impact on the dynamics of the soil moisture-precipitation feedback mechanism as the turbulent motions are not being captured as well at coarser resolutions. This will affect the transport of moisture and boundary layer dynamics, which both play a role in the feedback. Although only WP runs are shown, the same trend exists in FC and 50FC runs as well.

\subsection{Spatial scaling}

The scaling analysis was performed on 1000 to 1400 LT temporally averaged Bowen ratio using the first six statistical moments for each of the 12 days of model output. For FC there is a relatively strong relationship between the first moment and the third through sixth, while the second moment (variance) negatively affects the quality of the linear regression. In looking only at log-log plots of the variance versus resolution, in general strong linear relationships are seen, suggesting that the second moment scales with resolution and could be used to predict the spatial variance at any other resolution.

Ignoring the second moment for 50FC and WP would not bring as significant of an improvement in linear regressions, as fits in general would not be as good as those for FC. Additionally, on many days the log-log plots of variance versus resolution do not show as good fits as those seen in FC plots. Figure 9 shows time series of $R^{2}$ values and slopes from $\beta$ versus order of moment plots. With the exception of the first two days, slopes are similar for all three levels of soil moisture. FC generally has the lowest $R^{2}$ values, though these reflect the poorness of fit associated with the outlying second moments.

Plots of $\beta$ versus order of moment for soil temperature do not exhibit signs of scaling or multiscaling, meaning that they cannot be used to predict statistical properties at other resolutions. This is true for all levels of mean soil moisture. Figure 10 shows an example of such a plot for FC. Although $R^{2}$ values for FC 

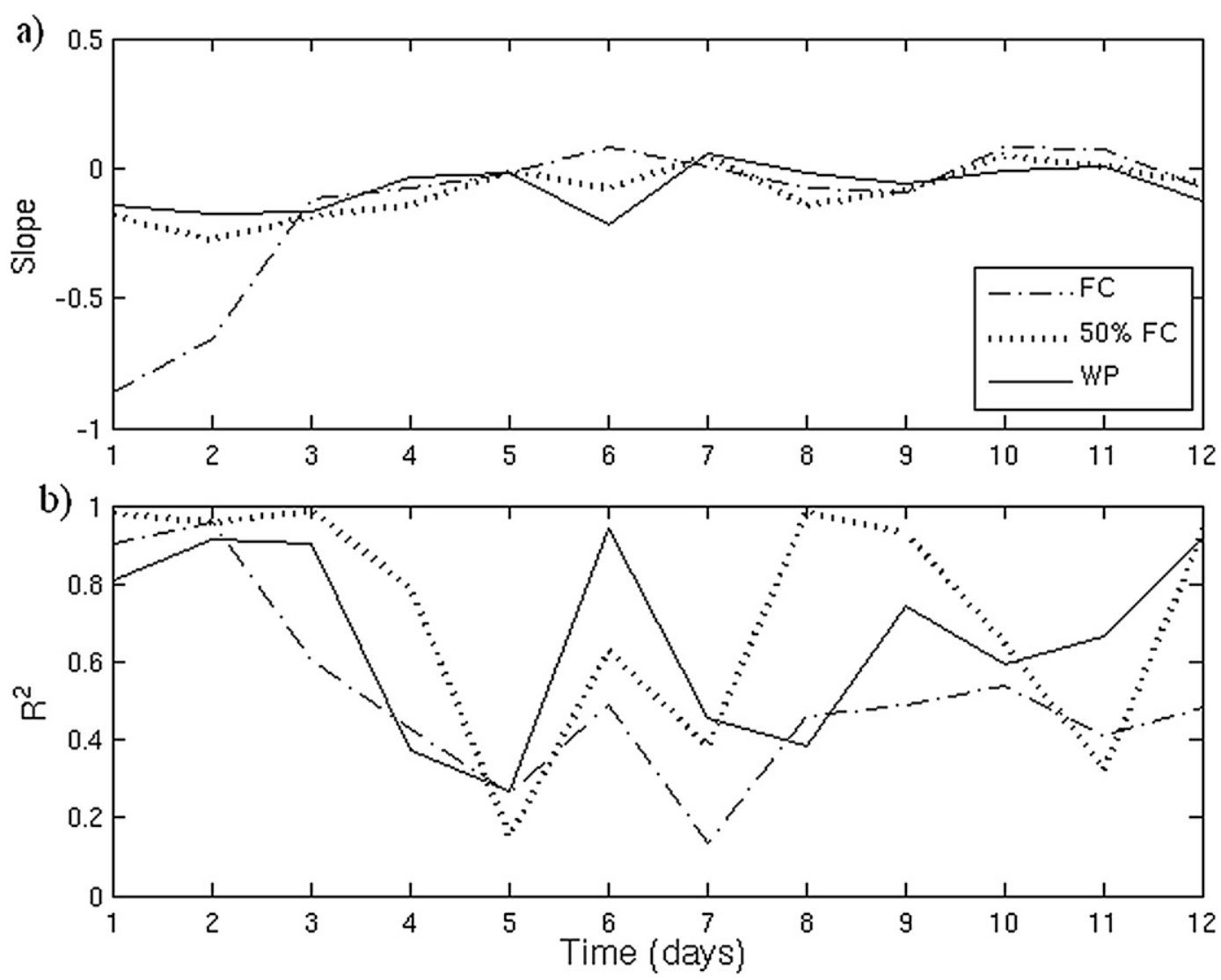

Figure 9. (a) Time series of slope from $\beta$ vs order of moment plots for Bowen ratio and (b) associated $R^{2}$ values.

(Figure 11) are relatively high, there is a significant amount of scatter in plots of $\beta$ versus order of moment for soil temperature.

Looking only at the second moment, log-log plots of variance versus resolution generally show good fits (Figure 12) for all levels of mean soil moisture. This indicates that these plots can be used to predict the variance of soil temperature fields at any other resolution, which may prove useful for the application of remotely sensed fields in future studies.

\section{Discussion}

The objective of this study was to determine which physical processes play a role in soil moisture-precipitation feedbacks and to examine how they vary as a function of mean soil moisture and resolution. A series of regional model runs focusing on the central plains were conducted as a first attempt to ascertain how the model responds to variation in the initial conditions and how this impacts the feedback between soil moisture and convective precipitation. While some have argued the importance of an increase in net radiation resulting from a lowering of 


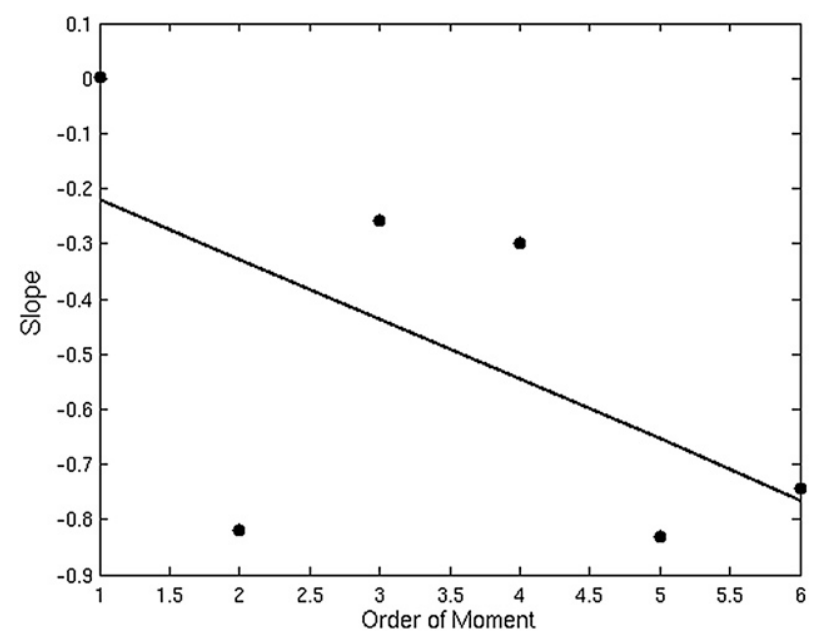

Figure 10. The $\beta$ vs order of moment plot for soil temperature FC day 2.

the albedo over moist soils, we have not found any evidence in the model to support this. In fact, based on our series of model runs we have shown that soil moisture did not have an impact on net radiation. This indicates that an increase in net radiation is not necessary for the occurrence of a positive soil moisture-precipitation feedback over moist soils.

We propose that the difference in energy balance partitioning associated with soil moisture plays a dominant role in determining whether a feedback occurs and that an increase in net radiation is not a necessary factor. Time series plots of mutual information content and scatterplots of soil moisture versus Bowen ratio and net radiation indicate that energy balance partitioning is heavily influenced by soil moisture. Surface properties (i.e., soil moisture, vegetative cover) collectively determine energy balance partitioning, which then influences turbulent motions and boundary layer depth.

An examination of turbulent mixing and boundary layer height showed smaller $\mathrm{km}_{v} / \mathrm{km}_{h}$ ratios and lower boundary layer height for FC runs than 50FC and WP. Lower sensible heat fluxes associated with FC runs resulted in less turbulent mixing and, as a result, shallower boundary layers. Drier soils were characterized by deeper boundary layers and larger turbulent motions resulting from higher sensible heat fluxes. Coarse spatial resolutions were unable to capture these turbulent motions in the boundary layer, which are necessary for convective processes. The effect of the model's inability to capture boundary layer turbulence is evident in plots of day of maximum lagged correlation. As resolution becomes coarser the day of maximum lagged correlation shifts from negative lags to positive lags (i.e., where latent heat was leading precipitation at fine resolutions, precipitation is now leading latent heat at coarse resolutions). The same is true for all of the variables examined: Bowen ratio, latent heat flux, sensible heat flux, and net radiation.

In terms of resolution, using plots of entropy for Bowen ratio, latent and sensible heat flux, and net radiation, we have shown that $1-\mathrm{km}$ runs consistently have a lower level of uncertainty associated with them. In general using a finer resolution 

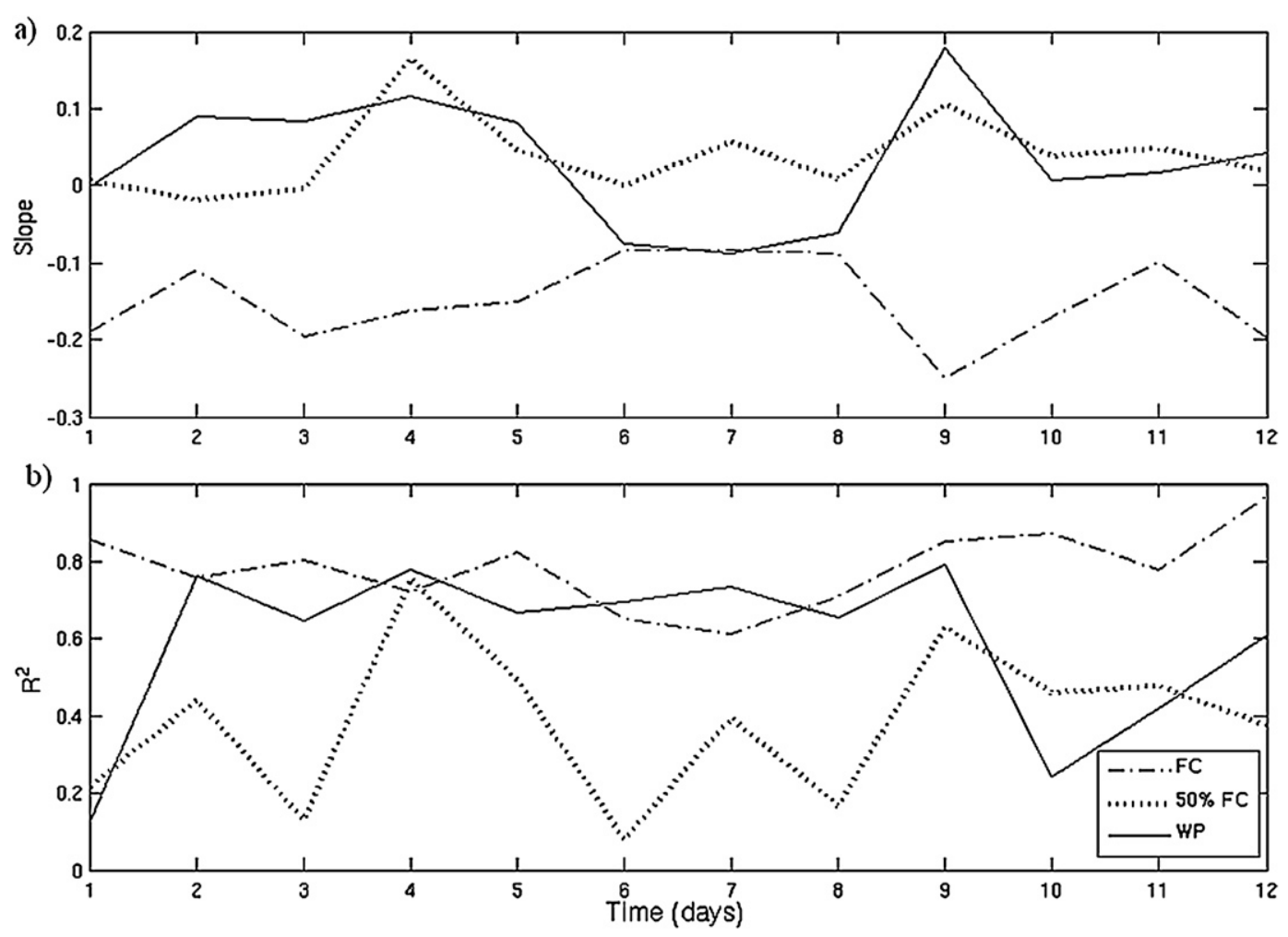

Figure 11. (a) Time series of slope from $\beta$ vs order of moment plots for soil temperature and (b) associated $R^{2}$ values.

provides greater information content or less uncertainty. In plots of lagged correlation, 1-km runs consistently had the highest correlation values regardless of mean soil moisture.

Plots of entropy, $\mathrm{km}_{v} / \mathrm{km}_{h}$ ratios, and lagged correlations all indicate that resolutions of $1 \mathrm{~km}$ or finer are necessary to capture the physical processes driving soil moisture-precipitation feedbacks and to potentially quantify the magnitude of such feedbacks in future work. The model's ability to resolve the physical processes involved in the feedback may result in inaccurate feedback magnitudes and may alter the spatial and temporal scales over which the feedback operates. We are moving toward a thorough understanding of the timing and the dependence on the initial value of the surface fields, which is essential in quantifying soil moistureprecipitation feedbacks.

The scaling analysis performed on 1000 to 1400 LT temporally averaged Bowen ratio showed a relatively strong relationship between soil moisture and the spatial scaling properties of the Bowen ratio. Despite this fact, $\log -\log$ plots of $\beta$ versus order of moment were not linear, meaning that the field is not self-similar and cannot be used to predict the statistical moments at resolutions other than the measurement scale.

Ignoring the second moment in FC plots generally provided good fits between the remaining moments. The second moment remained an outlier throughout each 


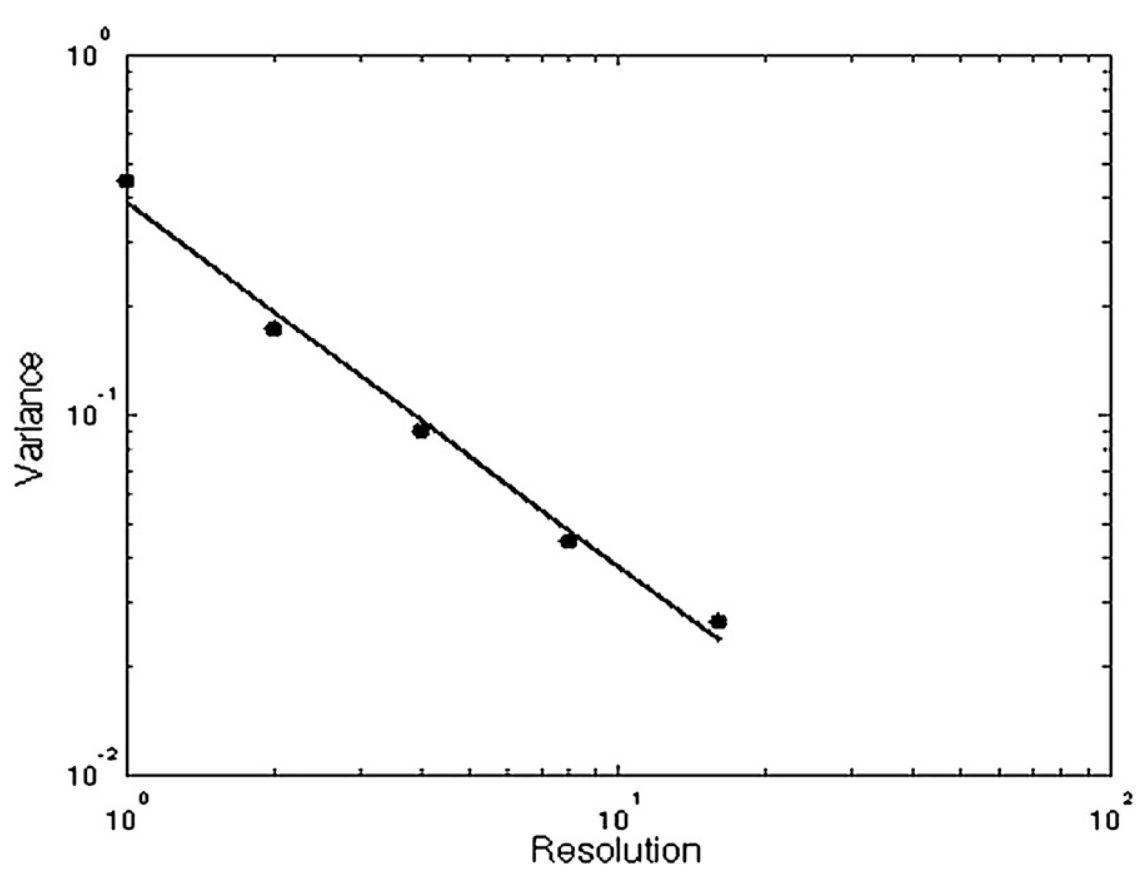

Figure 12. Scaling of the second moment (variance) for soil temperature from FC day 4.

of the 12 days examined, which warranted further investigation. Log-log plots of variance versus resolution for FC were created to look for signs of scaling in the variance of Bowen ratio fields (i.e., a linear relationship). These plots showed a strong linear relationship between variance and resolution, indicating that the variance does scale with resolution. Using this linear relationship the variance can be predicted at any resolution.

Although there were some days where these findings held true for 50FC and WP, in general they cannot be applied. This has negative implications for the potentially widespread applicability of using high-order statistical moments to scale remotely sensed fields, as the scaling characteristics are highly dependent on the soil moisture. In addition, scaling coefficients exhibit a relatively large amount of temporal variability; therefore, generalizations cannot be made. This will undoubtedly place limitations on the widespread applicability of this methodology, as the analysis would have to be performed with a relatively high temporal frequency.

Soil moisture did not have a significant affect on the scaling properties of 1000 to 1400 LT temporally average soil temperature. A scaling analysis of the first six moments showed that the fields do not exhibit self-similarity and therefore cannot be used to predict the statistical moments at other resolutions. In response to our findings for Bowen ratio fields, we again examined log-log plots of variance versus resolution to look for signs of scaling. With the exception of several days for each mean soil moisture value the plots were linear, indicating that variance does scale with resolution and therefore could be used to predict variance at any other resolution. Further analysis is required to determine how temporally variable the 
scaling coefficients for variance are. This will potentially impact the applicability for future studies. The relationships obtained through this study are, however, empirical scaling relationships and therefore must be examined under different environmental conditions at varying geographical locations.

As with any study there are associated limitations that may impact the context in which the conclusions may be viewed. Numerical models are a simplified representation of reality limited by our understanding of physical processes, a lack of input data at ideal spatial and temporal resolutions, and technological resources. The results of our study are at least to some extent dependent on our choice of model and parameterization schemes. For example, it is widely recognized that precipitation is highly dependent on the choice of convective scheme. For this reason we emphasize that the focus should not be placed on strict values of a variable but rather on how the values compare as a function of model resolution and mean soil moisture. A sensitivity analysis to parameterizations schemes would provide some indication as to the generality of our model results. Recommendations for future work include an increased number of mean soil moisture values and spatial resolutions.

\section{Conclusions}

Based on a series of regional model runs focusing on the central plains, it was found that energy balance partitioning played a significant role in determining the occurrence of soil moisture-precipitation feedback, while net radiation was not impacted by mean soil moisture. This could be in part a function of the vegetative cover, as previous studies have found that vegetation plays a role in determining net radiation. The important thing to note is that results indicate that a positive feedback still occurred despite the fact that a relationship between soil moisture and net radiation did not exist. Surface properties that impact albedo and net radiation (i.e., soil moisture and vegetative cover) influence turbulent motions and boundary layer depth through their impact on energy balance partitioning. Findings indicate that energy balance partitioning is heavily influenced by soil moisture and plays a large role in determining the magnitude of boundary layer depth and turbulence. The effects of vegetation were not examined but are assumed to play a major role. Coarse spatial resolutions were unable to capture turbulent motions in the boundary layer, which are necessary for convective processes. This undoubtedly has an impact on the ability of the model to accurately represent the dynamics of soil moistureprecipitation feedback, as the transport of moisture by turbulent motions will affect the spatial and temporal scales over which feedback occurs.

The results of this study indicate that resolutions of $1 \mathrm{~km}$ or finer are necessary to capture the physical processes driving soil moisture-precipitation feedbacks and for quantification of such feedbacks, which is an area requiring further study. Higher-resolution runs are generally associated with a higher information content. This relationship needs to be assessed at additional sites and under varying environmental conditions. If the relationship remains true, it would provide a methodology for monitoring soil moisture-precipitation feedbacks via remotely sensed vegetation and soil moisture fields. It would also provide a statistical indication of how much the resulting precipitation signal is dependent on soil moisture and vegetation fields at the resolution at which they were observed. 
Earth Interactions - Volume 13 (2009) • Paper No. 2 • Page 23

A scaling analysis performed on soil temperature and Bowen ratio indicated that mean soil moisture has a large impact on the scaling properties of Bowen ratio, while it did not appear to affect the scaling characteristics of soil temperature. There is the potential for large temporal variability in the scaling coefficients of both soil temperature and Bowen ratio, which may limit the large-scale applicability of this methodology to remotely sensed fields. Additional study is required to determine the amount of temporal variability in scaling coefficients of remotely sensed field.

The next step will be to compare the approaches used in this study with results obtained through field campaigns such as the Cloud and Land Surface Interaction Campaign (CLASIC) or the Southern Great Plains (SGP) field measurement site, where enough data exist to achieve a comparison; however, understanding the model's inherent scaling remains vital, particularly if the model is generally run at coarse resolutions. This study has shown that the model is incapable of capturing the dynamics of feedback between soil moisture and convective precipitation at coarse resolutions.

Acknowledgments. This work was supported the National Science Foundation EPSCOR Grant NSF EPS 0553722. In addition we thank the work of two anonymous reviewers who greatly enhanced this manuscript.

\section{References}

Baldocchi, D. D., T. Krebs, and M. Y. Leclerc, 2005: "Wet/dry daisyworld": A conceptual tool for quantifying the spatial scaling of heterogeneous landscapes and its impact on the subgrid variability of energy fluxes. Tellus, 57B, 175-188.

Barros, A. P., and W. Hwu, 2002: A study of land-atmosphere interactions during summertime rainfall using a mesoscale model. J. Geophys. Res., 107, 4227, doi:10.1029/2000JD000254.

Bloschl, G., 1996: Scale and Scaling in Hydrology (Habilitationsschrift). Vol. 132, Vienna Communications: Water, Wastewater, Fluids, Institute for Hydraulics, Vienna, Austria, 346 pp.

—, 2001: Scaling in hydrology. Hydrol. Processes, 15, 709-711.

Brunsell, N. A., 2006: Characterization of land-surface precipitation feedback regimes with remote sensing. Remote Sens. Environ., 100, 200-211.

— wavelets: Application to SGP97. Int. J. Remote Sens., 24, 2945-2957.

$\longrightarrow$, and 2003b: Scale issues in land-atmosphere interactions: Implications for remote sensing of the surface energy balance. Agric. For. Meteor., 117, 203-221.

— NEXRAD data. Int. J. Remote Sens., 29, 1965-1982.

— J. M. Ham, and C. E. Owensby, 2008: Assessing the multi-resolution information content of remotely sensed variables and elevation for evapotranspiration in a tall-grass prairie environment. Remote Sens. Environ., 112, 2977-2987.

Chen, F., and R. Avissar, 1994: Impact of land-surface moisture variability on local shallow convective cumulus and precipitation in large-scale models. J. Appl. Meteor., 33, 1382-1401.

Cook, B. I., G. B. Bonan, and S. Levis, 2006: Soil moisture feedbacks to precipitation in southern Africa. J. Climate, 19, 4198-4206. 


\section{Earth Interactions • Volume 13 (2009) • Paper No. 2 • Page 24}

Deidda, R., 1999: Multifractal analysis and simulation of rainfall fields in space. Phys. Chem. Earth, 24, 73-78.

Dong, J., W. Ni-Meister, and P. R. Houser, 2007: Impacts of vegetation and cold season processes on soil moisture and climate relationships over Eurasia. J. Geophys. Res., 112, D09106, doi:10.1029/2006JD007774.

Dubayah, R., E. F. Wood, and D. Lavallee, 1997: Multiscaling analysis in distributed modeling and remote sensing: An application using soil moisture. Scale in Remote Sensing and GIS, D. A. Quatrochi and M. F. Goodchild, Eds., Lewis Publishers, 93-112.

Eltahir, E., 1998: A soil moisture-rainfall feedback mechanism. Part I: Theory and observations. Water Resour. Res., 34, 765-776.

Fay, P. A., J. D. Carlisle, A. K. Knapp, J. M. Blair, and S. L. Collins, 2003: Productivity responses to altered rainfall patterns in a C4-dominated grassland. Oecologia, 137, 245-251.

Findell, K. L., and E. A. B. Eltahir, 1997: An analysis of the soil moisture-rainfall feedback, based on direct observations from Illinois. Water Resour. Res., 33, 725-735.

— Framework development. J. Hydrometeor., 4, 552-569.

— Feedbacks within the continental United States. J. Hydrometeor., 4, 570-583.

Gupta, V. K., and E. Waymire, 1990: Multiscaling properties of spatial rainfall and river flow distributions. J. Geophys. Res., 95, 1990-2009.

Halley, J. M., S. Hartley, A. S. Kallimanis, W. E. Kunin, J. J. Lennon, and S. P. Sgardelis, 2004: Uses and abuses of fractal methodology in ecology. Ecol. Lett., 7, 254-271.

Jones, A. R., and N. A. Brunsell, 2008: A scaling analysis of soil moisture-precipitation interactions in a regional climate model. Theor. Appl. Climatol., submitted.

Juang, J.-Y., A. Porporato, P. C. Stoy, M. S. Siqueira, A. C. Oishi, M. Detto, H.-S. Kim, and G. G. Katul, 2007: Hydrologic and atmospheric controls on initiation of convective precipitation events. Water Resour. Res., 43, W03421, doi:10.1029/2006WR004954.

Kaste, J. M., A. M. Heimsath, and M. Hohmann, 2006: Quantifying sediment transport across an undisturbed prairie landscape using cesium-137 and high resolution topography. Geomorphology, 76, 430-440.

Koster, R. D., and Coauthors, 2004: Regions of strong coupling between soil moisture and precipitation. Science, 305, 1138-1140.

Lett, M. S., and A. K. Knapp, 2005: Woody plant encroachment and removal in mesic grassland: Production and composition responses of herbaceous vegetation. Amer. Midl. Nat., 153, 217-231.

Nippert, J. B., A. K. Knapp, and J. M. Briggs, 2006: Intra-annual rainfall variability and grassland productivity: Can the past predict the future? Plant Ecol., 184, 65-74.

Pal, J. S., and E. A. B. Eltahir, 1996: Relationship between surface conditions and subsequent rainfall in convective events. J. Geophys. Res., 101, 26 237-26 245.

— and _ 2001: Pathways relating soil moisture conditions to future summer rainfall within a model of the land-atmosphere system. J. Climate, 14, 1227-1242.

Peters-Lidard, C. D., F. Pan, and E. F. Wood, 2001: A re-examination of modeled and measured soil moisture spatial variability and its implications for land surface modeling. Adv. Water Resour., 24, 1069-1083.

Rodriguez-Iturbe, I., G. K. Vogel, R. Rigon, D. Entekhabi, F. Castelli, and A. Rinaldo, 1995: On the spatial organization of soil moisture fields. Geophys. Res. Lett., 22, 2757-2760.

Shannon, C. E., 1948: A mathematical theory of communication. Bell Syst. Tech. J., 27, 379-423.

Teuling, A. J., and S. I. Seneviratne, 2008: Contrasting spectral changes limit albedo impact on land-atmosphere coupling during the 2003 European heat wave. Geophys. Res. Lett., 35, L03401, doi:10.1029/2007GL032778.

Waymire, E., 1985: Scaling limits and self-similarity in precipitation fields. Water Resour. Res., 21, 1271-1281. 
Western, A. W., and G. Bloschl, 1999: On the spatial scaling of soil moisture. J. Hydrol., 217, 203-224.

Xue, M., K. K. Droegemeier, and V. Wong, 2000: The Advanced Regional Prediction System (ARPS) - A multi-scale nonhydrostatic atmospheric simulation and prediction model. Part I: Model dynamics and verification. Meteor. Atmos. Phys., 75, 161-193.

_ _ and Coauthors, 2001: The Advanced Regional Prediction System (ARPS)—A multi-scale nonhydrostatic atmospheric simulation and prediction model. Part II: Model physics and applications. Meteor. Atmos. Phys., 76, 143-165.

Earth Interactions is published jointly by the American Meteorological Society, the American Geophysical Union, and the Association of American Geographers. Permission to use figures, tables, and brief excerpts from this journal in scientific and educational works is hereby granted provided that the source is acknowledged. Any use of material in this journal that is determined to be "fair use" under Section 107 or that satisfies the conditions specified in Section 108 of the U.S. Copyright Law (17 USC, as revised by P.IL. 94553) does not require the publishers' permission. For permission for any other from of copying, contact one of the copublishing societies. 